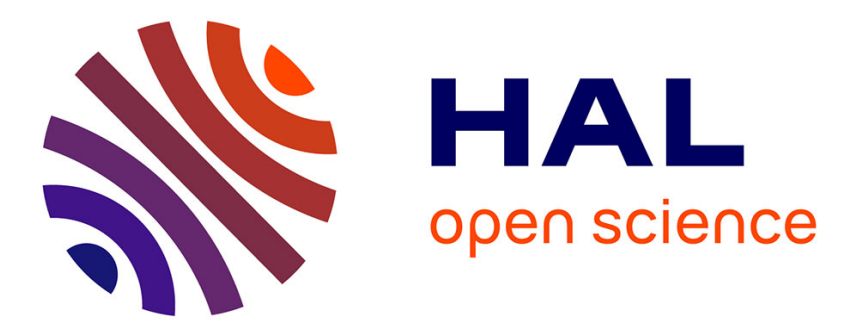

\title{
Electron paramagnetic resonance of radicals induced in drugs and excipients by radiation or mechanical treatments
}

J Raffi, S Gelly, L Barral, F Burger, P Piccerelle, P Prinderre, Michel Baron, Alain Chamayou

\section{To cite this version:}

J Raffi, S Gelly, L Barral, F Burger, P Piccerelle, et al.. Electron paramagnetic resonance of radicals induced in drugs and excipients by radiation or mechanical treatments. Spectrochimica Acta Part A: Molecular and Biomolecular Spectroscopy [1994-..], 2002, 58 (6, SI), p.1313-1320. 10.1016/S13861425(01)00720-X . hal-01632799

\section{HAL Id: hal-01632799 https://hal.science/hal-01632799}

Submitted on 8 Nov 2019

HAL is a multi-disciplinary open access archive for the deposit and dissemination of scientific research documents, whether they are published or not. The documents may come from teaching and research institutions in France or abroad, or from public or private research centers.
L'archive ouverte pluridisciplinaire HAL, est destinée au dépôt et à la diffusion de documents scientifiques de niveau recherche, publiés ou non, émanant des établissements d'enseignement et de recherche français ou étrangers, des laboratoires publics ou privés. 


\title{
Electron paramagnetic resonance of radicals induced in drugs and excipients by radiation or mechanical treatments
}

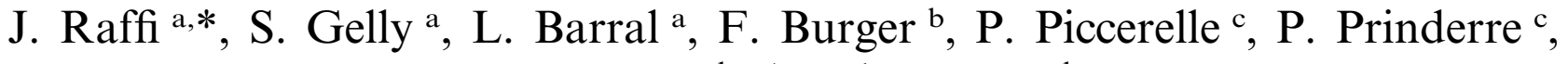 \\ M. Baron ${ }^{\mathrm{d}}$, A. Chamayou ${ }^{\mathrm{d}}$ \\ ${ }^{a}$ LARQUA/LRMO, Faculté des Sciences de Saint-Jérôme, case D52, 13397 Marseille cedex 20, France \\ ${ }^{\mathrm{b}}$ LMRE, Faculté des Sciences de Saint-Jérôme, case D52, 13397 Marseille cedex 20, France \\ ${ }^{\mathrm{c}}$ Laboratoire de Pharmacie Galénique Industrielle et Cosmétologie, 27 Boulevard Jean Moulin, 13385 Marseille cedex 5, France \\ ' Laboratoire de Génie des Procédés des Solides Divisés, UMR CNRS 2392, Ecole des Mines d'Albi-Carmaux, \\ 81013 Albi CT cedex 09, France
}

\begin{abstract}
Radiation as well as mechanical treatments induced in drugs and excipients radicals, which can be studied by electron paramagnetic resonance. A special attention is pointed about the use of electron paramagnetic resonance (EPR) to bring the proof whether or not a drug has been irradiated or not. We also discuss of other methods (thermoluminescence (TL), gas phase chromatography (GPC)) which can be used to bring the same proof in case of irradiated drugs, excipients and cosmetic products. (C) 2002 Elsevier Science B.V. All rights reserved.
\end{abstract}

Keywords: Electron paramagnetic resonance; Thermoluminescence; Drug; Radiation; Mechanical treatment

\section{Introduction}

Gamma rays and electron beams have been used for a long time in order to sterilise medical devices. This treatment will be more and more applied for sterilisation of drugs [1,2]. As for foodstuffs [3,4], it could be interesting to be able to prove whether or not a drug has been irradiated.

Active ingredients may be irradiated alone but also in mixtures with a lot of products; thus we

* Corresponding author. Tel./fax: + 33-4-91-985055.

E-mail address: j.raffi@univ.u-3mrs.fr (J. Raffi). can find natural vegetal products (starch, cellulose,...) more or less modified and simple sugars used as excipients. For active ingredients we took the example of some antibiotics but also the one of simple products such as amino acids; for instance leucine can be used, due to its ability to stimulate or modulate translation initiation factors in rat liver [5,6], translation initiation in skeletal muscles [7], arginine produces beneficial effects on the heart rate and tissue oxygen extraction in haemorrhaged rabbits [8], tyrosine transport pathway may be used to improve nasal absorption of poorly permeable drugs [9], dimethylglycine leads to a significant reduction in 
glutathione levels [10], and a lot of amino acids are given as nutritional complements for some patients [11].

One opportunity is to detect by electron paramagnetic resonance (EPR) the radicals induced in solid and relatively dry state; in these conditions the induced and trapped radicals may have a long life time (up to several months or years). In the first part of this paper, we shall give examples of such radicals; but we also show that the only presence of radicals is not a proof of irradiation, as radicals may also be induced by grinding, UV-radiation.... Thus we must take precautions before to ascertain any conclusion

In a second part we will see how thermoluminescence (TL) and gas phase chromatography (GPC) can also be used.

\section{Experimental}

\subsection{Grinding experiments}

Grinding experiments were performed at room temperature in a vibro-activator (one-ball vibration mill of type Dangoumau, Fig. 1). Dangoumau grinder has be used [12] to study phase transformations of minerals, and recently to increase bioavailability of drugs by co-grinding [13]. The theoretical prediction of dynamic regimes in the vibro-activator was published lately [14]. The quantity of induced radicals depends on the grinding time; a too long time destroys the radicals, probably by heating of the medium and/or recombination of radicals [15], in most cases a time of 10-15 min leads to a maximal quantity of radicals.

\subsection{Irradiations}

There were performed at room temperature in the 'CIGAL' cell of Cadarache $(50000 \mathrm{Ci}$ of cobalt 60) supplying a dose rate of $6.1 \mathrm{kGy} \mathrm{h}^{-1}$. Storage of samples was always at room temperature and in absence of light.

\subsection{EPR and TL measurements}

The EPR spectra were recorded at room temperature with a Bruker EMS104 spectrometer with the following average conditions: Microwave power, $0.79 \mathrm{~mW}$; sweep width, $20 \mathrm{mT}(200 \mathrm{G})$; modulation, $0.4 \mathrm{mT}(4 \mathrm{G})$; number of sweeps, $3-55$, respectively, for radiation or mechanical induced radicals.

The TL spectra were recorded with a Harshaw 4000 A apparatus with the following average conditions: initial temperature, $50{ }^{\circ} \mathrm{C}$, during $10 \mathrm{~s}$; final temperature, $350{ }^{\circ} \mathrm{C}$; increasing temperature rate, $8{ }^{\circ} \mathrm{C} \mathrm{s}^{-1}$.

\section{Results and discussion}

3.1. ESR study of gamma induced radicals in drugs and excipients

A lot of drugs and excipients can be irradiated

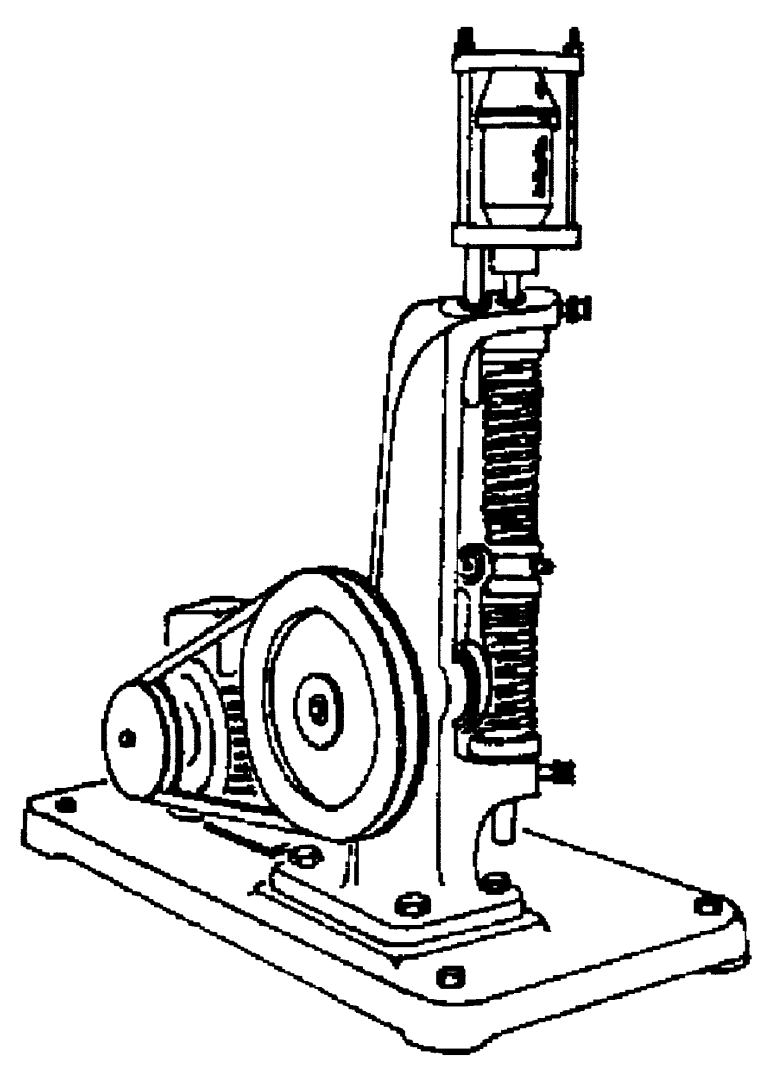

Fig. 1. One-ball vibration mill of type Dangoumau. 


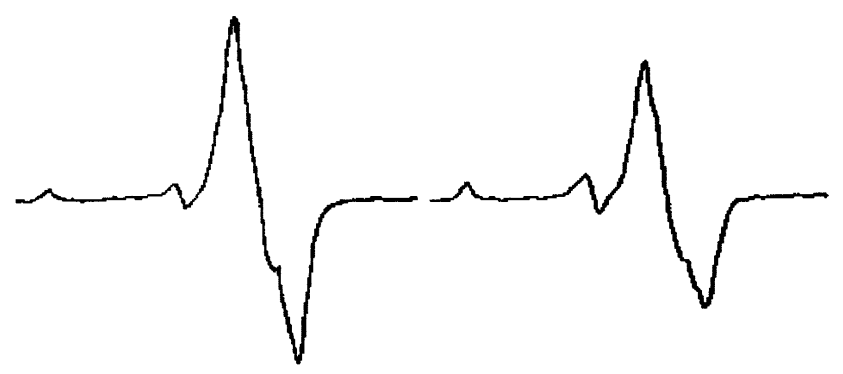

Fig. 2. EPR spectra of radicals induced in anhydrous ampicilline acid just after a $50 \mathrm{kGy}$ irradiation (left) and 6 months later (right).

in solid state; generally they show no EPR signal in the unirradiated sample which is consequently very easy to be detected.

On another hand, the irradiated drugs present complex spectra; these drugs being dry, the life time of the signals induced by radiation is very long, several months or years; Fig. 2 shows the example of an irradiated antibiotic, anhydrous ampicilline acid $[16,17]$ which presents a large and very stable signal (more than 1 year).

Consequently, ESR detection of irradiated drugs must be very easy. However, in case of natural products used in some drugs, the unirradiated sample may also present a single line very often found in vegetal products, probably due to a quinone radical $[4,18]$; but the single line is easy to be distinguished from the complex signal induced in irradiated drugs and is not, consequently, a limit to the detection of an irradiated sample.

The case of amino-acids (Fig. 3) seems also simple: the unirradiated samples show no ESR signal, and the irradiated ones show large signals, more or less complex, depending on the chemical nature of the amino-acid. Generally, the storage time is very important (several months, even years) and even used, in case of alanine, for dosimetry [19,20]; for some of them a storage time of 2 years does not show any important evolution in the shape of the EPR signal (alanine, arginine, glycine); to see such an evolution, it is necessary to heat the sample during several hours at $70{ }^{\circ} \mathrm{C}$ (for example, glycine). The great majority of amino-acids (histidine, lysine, proline, tyrosine,
...) show an evolution of the shape of their EPR spectra but the signal is always very important, 2 years after irradiation, allowing an easy detection of the treatment. But in some other cases the life time can be very short (several weeks for cysteine and valine to only 2-3 days for leucine); moreover, due to the distance between the irradiator and the laboratory (about a $2 \mathrm{~h}$ car drive), we have observed no signal after a $5 \mathrm{kGy}$ room temperature irradiation of methionine! It was also the same in case of irradiation of a lyophilised collagen dressing whatever the radio-induced ef-
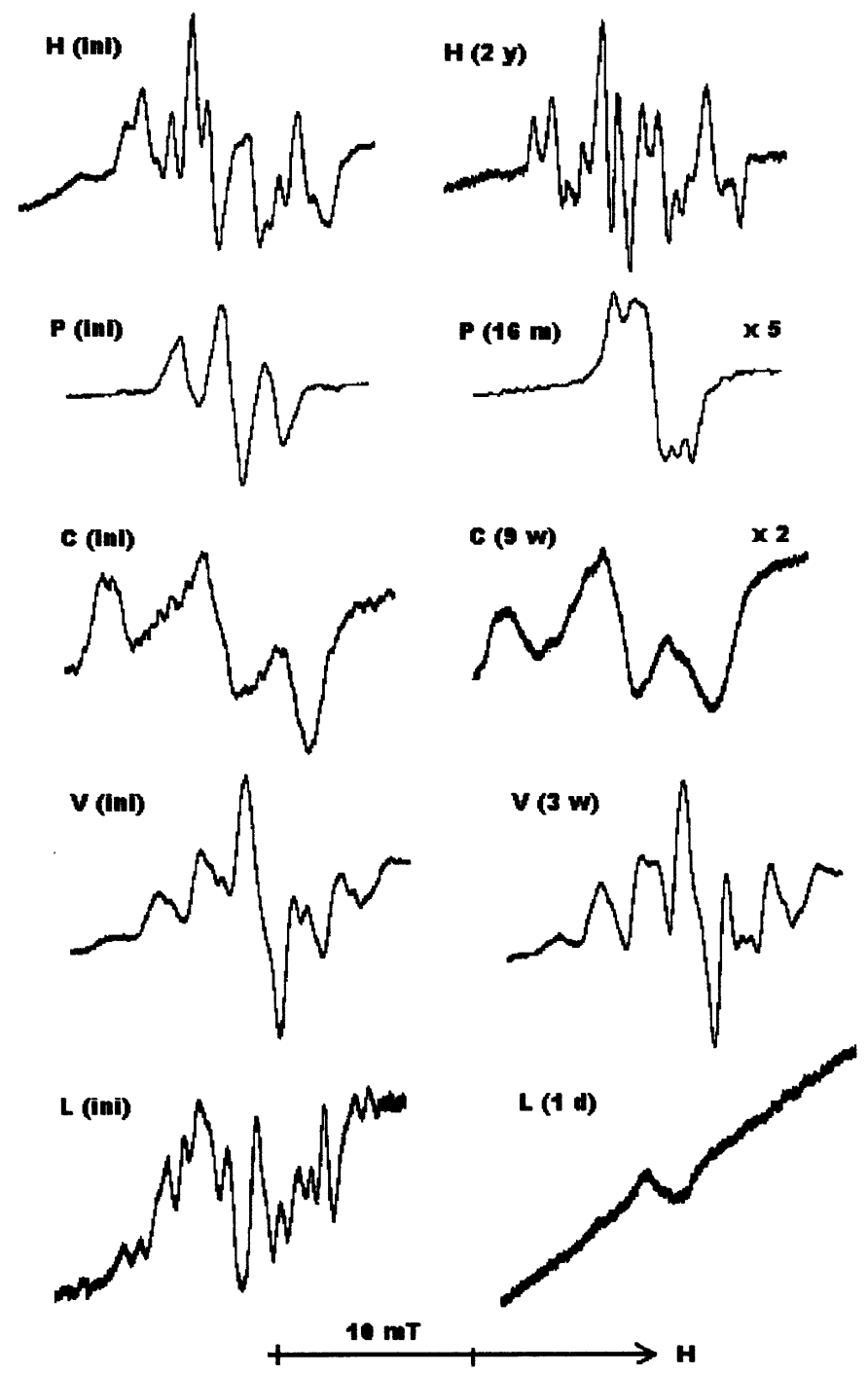

Fig. 3. EPR spectra of some irradiated amino-acids $(\mathrm{H}=$ histidine, $\mathrm{P}=$ proline, $\mathrm{C}=$ cysteine, $\mathrm{V}=$ valine, $\mathrm{L}=$ leucine; ini $=$ just after irradiation, $\mathrm{y}=$ year, $\mathrm{m}=$ month, $\mathrm{w}=$ week, $\mathrm{d}=$ day; other recording conditions in the text). 

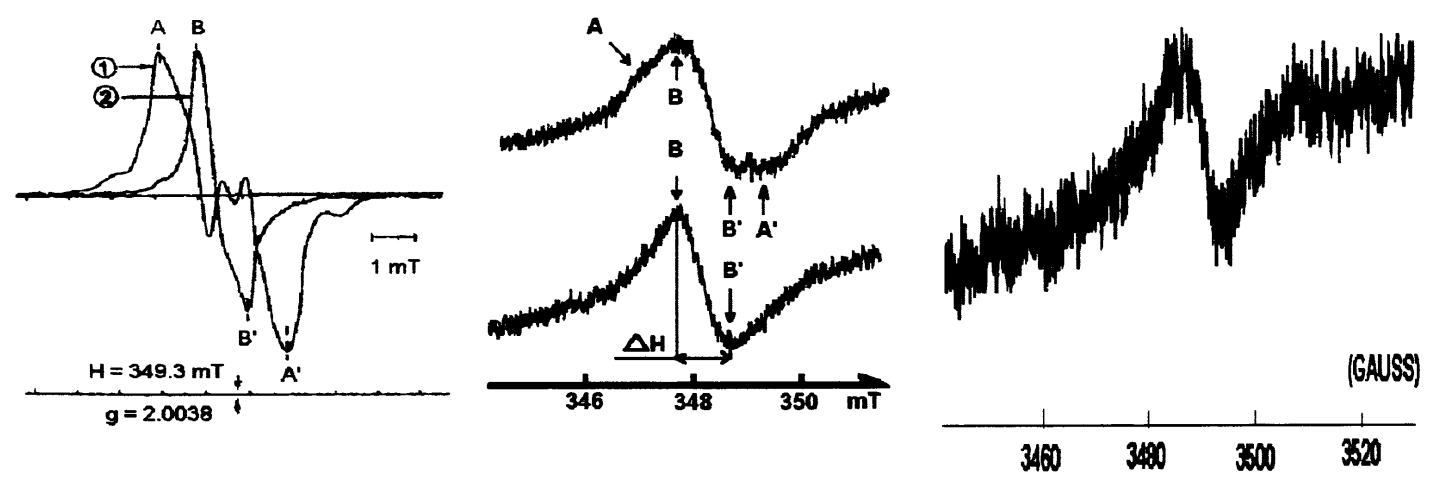

Fig. 4. EPR signals of radicals induced in starches by gamma radiation (A), UV radiation (B) or grinding (C). (A) Curve 1 recorded just after gamma irradiation, curve 2 recorded 6 months later (gain multiplied by 20). (B) Upper curve recorded just after UV irradiation, curve 2 recorded several hours later.

fects observed by other techniques such as microelectrophoresis or electronic microscopy [21]. Thus the fundamental studies [22-25] must be reoriented to find what would be the life time of the ESR signals, product per product: the presence of an EPR signal will be a proof of irradiation but its absence will not be a proof of no irradiation, at least for some amino acids.

In excipients such as starch [26] (Fig. 4(A)), cellulose, mannitol... there is no signal or a simple singulet in the unirradiated sample and a complex EPR signal, relatively stable with time (at least in crystalline parts) in the irradiated samples. Here too the detection of an irradiation treatment will be easy, under the condition that the signal shape is characteristic of irradiation, which was not always the case (the storage time of cereals may be greater than 1 year) [27].

\subsection{ESR study of radicals induced by other treatments}

We have only to consider here the radicals induced in solid state; it is well known that thermal or ultrasound [28-31] treatments induced radicals but they disappear very quickly as they are always induced in 'liquid state'.

However, we should be note that radicals detected by EPR can also be induced by other treatments such as UV radiation [32,33] or by mechanistic action such as grinding even if radical were induced in very small quantities [34-38]. For instance, Fig. 4 shows that the main radicals induced by gamma (Fig. 4(A)) [26] or UV radiation (Figs. 1-4) [39,40], or by grinding (Fig. 4(C)) are identical; other excipients such as lactose (Fig. 5(A)), carboxymethylcellulose (Fig. 5(B)), cellulose, mannitol,... [15] may also present ESR signals due to grinding but these signals are always very weak with regard to the ones radio-induced in drugs. Thus we can consider that, for a synthetic drug, there is no signal at all present in the unirradiated sample.

Let us point out another fact. The fact that we observe the same radicals whatever is the treatment (gamma or UV radiation, or grinding) only means that we observe at room temperature the same more stable and, consequently, the more probable radicals, the primary mechanisms are different! This also means that the presence of radicals in a solid such as a drug is not a proof of an irradiation treatment; the proof is the fact that we observe relatively large quantities of radicals inside the whole sample, UV only induces radicals at the outside of the product; thermal radicals are destroyed in the same time they are produced (bimolecular reactions in liquid phase).... 


\subsection{Thermoluminescence (TL) measurements}

Here too this method must be applied to drugs irradiated in powder and dry state, allowing the detection of radio-induced ions trapped in the solid matrix. On the opposite of the protocol used for detection of irradiated foodstuffs where the TL signal is due to silicate impurities [41,42], there is no problem of extraction as the TL signal is recorded on the whole sample $[16,43]$.

But the study may be more complex. First at all, the unirradiated sample presents as the unirradiated one a TL spectra, for instance two peaks in case of anhydrous ampicilline acid (Fig. 6(A)); in this very favourable case, the two peaks vary on different ways with regard to the irradiation dose (Fig. 6(B)) and thus lead to a proof of irradiation; moreover, we can distinct the products irradiated at 25-30 kGy (usual dose range for sterilisation) from those only irradiated at $10 \mathrm{kGy}$ (final 'barrier treatment'). But in other close antibiotics, the peaks may have very different variations [43]:

- in case of the three-hydrated amoxicilline acid, the first peak increases with regard to the second with increasing doses, i.e. just the opposite of anhydrous ampicilline acid! It is approximately the same for the monohydrated sodium salt of cloxacilline;

- in case of pentahydrated ceftazidime, there are two peaks which seems to have a constant ratio with regard to the dose.
Consequently, each drug is a different case and requires a specific study. There will not be a general detection protocol as in case of foodstuffs [41].

Moreover, in case of mixtures, which is often the case, it will be impossible to attribute the observed TL signal to a special product; thus the method will be limited to pure products. On another hand, in case of vegetal ingredients, the foodstuffs protocol [41] may be applied.

\subsection{A comment on the use of gas phase chromatography}

In case of drugs not irradiated in solid state, we can make the hypothesis that the protocol devoted to foodstuffs containing lipids [44,45] may be applied. Let us remember that, when such foodstuffs are irradiated, the percentage of radioinduced hydrocarbons is directly linked to the chemical composition of lipids; this is due to the fact that, when fatty acids are exposed to high energy radiation, they undergo preferential cleavages, unlike other treatments, in the ester carbonyl region; the two main hydrocarbons, derived from each fatty acid of structure $C(n: m)$ are those of structure $C(n-1: m)$, with one carbon less than the parent fatty acid and of structure $C(n-$ $2: m+1)$, with two carbons less and one extra double bond. The method was successfully ap-
(A)

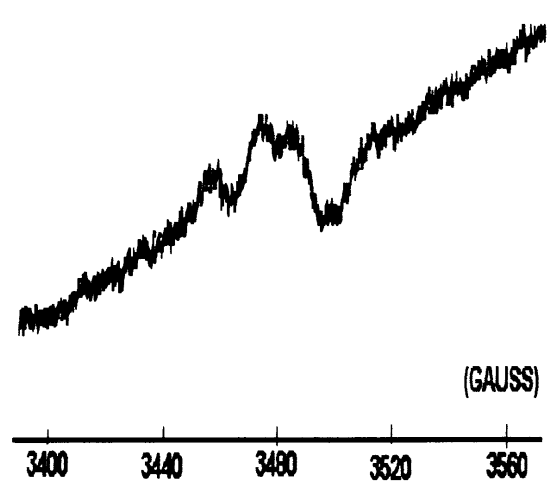

(B)

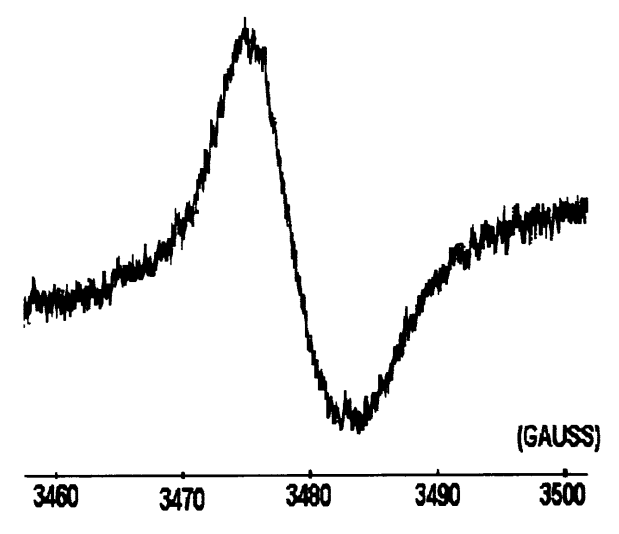

Fig. 5. EPR spectra of radicals induced by grinding in lactose (A) and carboxymethylcellulose (B). 

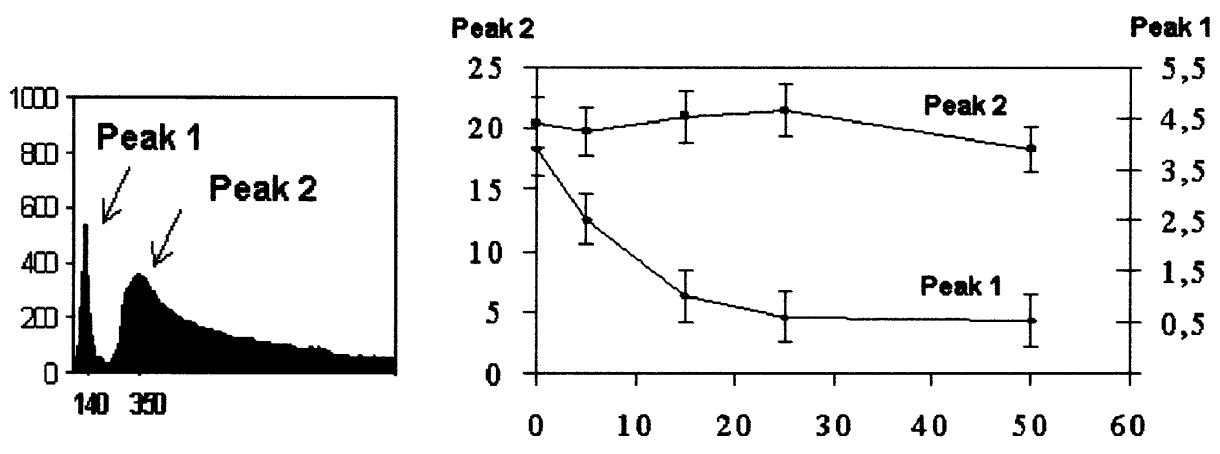

Fig. 6. TL recording (left) of unirradiated anhydrous ampicilline acid and variation of peak intensities (right) with irradiation dose (kGy).

LIPIDS
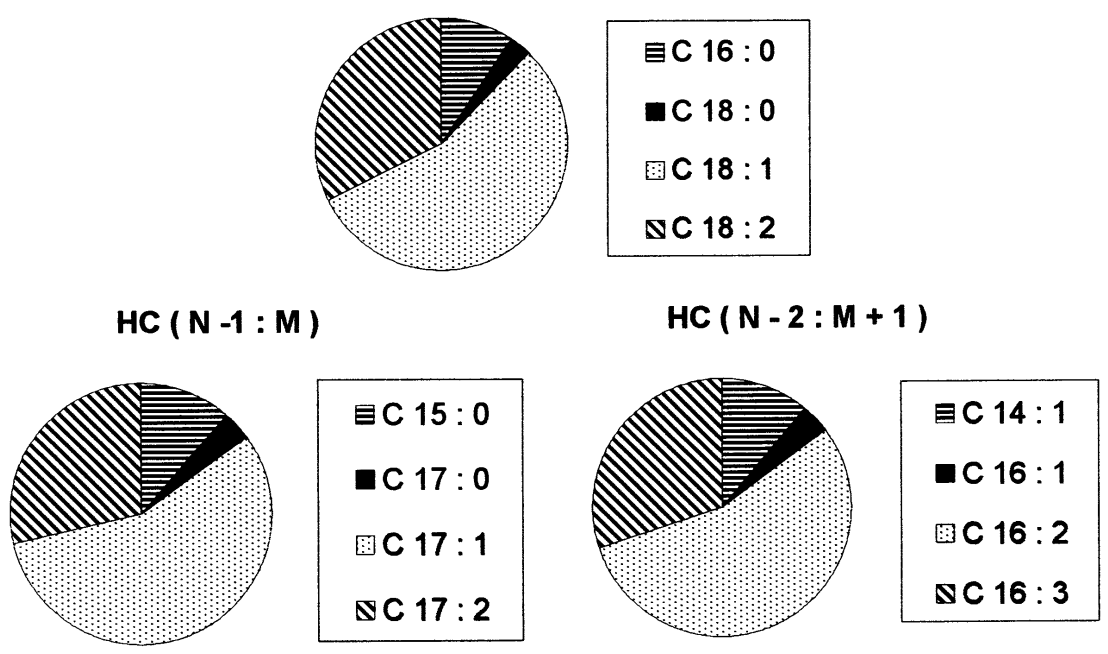

Fig. 7. Compositions (in \%) of lipids and radio-induced hydrocarbons in a mixture (1/1/1) of peanut, sunflower and extra virgin olive oils.

plied to foodstuffs with a maximum of three or four main lipids, that it to say representing more than $95 \%$ of the total lipids composition [46], Fig. 7 shows the example of a synthetic mixture $(1 / 1 / 1)$ of peanut, sunflower and olive oils irradiated at 5 kGy.

In fact the problem will be that main cosmetic products, or creams used as vectors in pharmacopoeia to transfer active ingredients through the skin, have complex compositions which probably does not allow us to reach, in each case, a proof of the irradiation treatment. Moreover, these products also contain phospholipids, which may do not follow the same radiolysis rules than the other lipids.

\section{Conclusions}

Thus, whatever is the studied drug or excipient irradiated in solid state, there will be no problem to detect its irradiation treatment by EPR. However, on a fundamental point of view, there will be a lot of experiments to carry out in order to improve the knowledge of the structure radio-induced radicals, at least in case of drugs; the case of excipients is generally relatively well known. Let us just notice that an absence of an EPR signal will be a proof of non irradiation treatment in the only case where the products are crystallised without water; in case of amorphous structures, initial researches must be carried out in 
order to study the stability of radicals with regard to the storage time and parameters.

On another hand, the presence of an EPR signal in a complex mixture (excipients + drugs) will probably bring the proof of an irradiation treatment at least on one of the components but it will be very difficult to find the nature of this irradiated component... except if it is the only one treated by gamma rays. This ambiguity comes from the following facts:

- all organic radicals show EPR signals approximately centred in the same area, $350 \mathrm{mT}$ for 9.5 GHz spectrometers;

- in solid phase, the EPR spectra are quite always poorly resolved, due to the overlapping of the different spectra relative to the different directions of initial spins with regard to the magnetic field.

More generally, we can ascertain that, for drugs and cosmetic products, we can write in the future some protocols of detection of an irradiation treatment if:

- the product is irradiated in solid and dry state, by ESR in quite every case, and by TL at least in some cases;

- the product is rich in lipids, by GPC, at least in some cases.

But, before writing these protocols, there will be a lot of fundamental researches to carry out.

\section{Acknowledgements}

We have to thank José Vicente (CEA/DSV/ DEVM, Cadarache) for carrying out the irradiations.

\section{References}

[1] P. Piccerelle, J.-P. Reynier, J. Joachim, B. Tilquin, J. Raffi, Radio-stérilisation de médicaments: intérêt, législation et travaux à entreprendre, J. Pharma. Belg. 55 (2000) $131-136$.

[2] H. Ambroz, E. Kornacka, B. Marciniec, M. Ogrodowczyk, G. Przybytniak, EPR study of free radicals in some drugs gamma-irradiated in the solid state, Radiat. Phys. Chem. 58 (2000) 357-366.

[3] L. Douifi, J. Raffi, P. Stocker, F. Dole, A point about
EPR detection of irradiated foodstuffs, Spectrochim. Acta (A) 54 (1998) 2403-2412.

[4] J. Raffi, Identifying irradiated foods, Trends Anal. Chem. 17 (1998) 226-233.

[5] O.J. Shah, D.A. Antonetti, S.R. Kimball, L.S. Jefferson, Leucine, glutamine and tyrosine reciprocally modulate the translation initiation factors eIF4F and eIF2B in perfused rat liver, J. Biol. Chem. 274 (1999) 36168-36175.

[6] T.G. Anthony, J.C. Anthony, F. Yoshizawa, S.R. Kimball, L.S. Jefferson, Oral administration of leucine stimulates ribosomal protein mRNA translation but not global rates of protein synthesis in the liver of rats, J. Nutrition 131 (2001) 1171-1176.

[7] J.C. Anthony, F. Yoshizawa, T. Gautsch-Anthony, T.C. Vary, L.S. Jefferson, S.R. Kimball, Leucine stimulates translation initiation in skeletal muscle of post-absorptive rats via a rapamycin-sensitive pathway, J. Nutrition 130 (2000) 2413-2419.

[8] Z. Todorovic, M. Prostran, S. Vuckocic, The influence of L-arginine on heart rate and tissue oxygen extraction in haemorrhaged rabbits, Pharmacol. Res. 43 (2001) $321-$ 327.

[9] C. Yang, A.K. Mitra, Nasal absorption of tyrosine-linked model compounds, J. Pharm. Sci. 90 (2001) 340-347.

[10] K. Hariganesh, J. Prathiba, Effect of dimethylglycine on gastric ulcers in rats, J. Pharm. Pharmacol. 52 (2000) $1519-1522$.

[11] Anonymous, Nutrineal PD4 (Baxter), BIAM (Banque de Données Automatisée sur les médicaments; www.BIAM2.org) 31 August 1998.

[12] J.L. Dandurant, Contribution à l'étude des effets du broyage sur les transformations physicochimiques des matériaux, Doctorat d'Etat $N^{\circ} 820$, Université Paul Sabatier, Toulouse (1978).

[13] M. Baron, J. Dodds, A. Chamayou, S. Pakkanen, J.O. Larsen, G. Nachon, L. Oudet, P. Tchoreloff, G. Couarraze, Co-broyage de principes actifs pharmaceutiques pour améliorer leur biodisponibilité, Colloque CNRS, Toulouse 26-27 Novembre 1998.

[14] V.E. Mizonov, A.A. Kurbatov, M. Baron, A. Chamayou, Z.P. Zhukov, Calculation of dynamic regimes of vibrator activation of fine powders (in Russian), Chem. Chem. Technology 1 (2001).

[15] M. Kuzuya, S.-I. Kondo, A novel collision-induced solid state radical recombination, Mol. Cryst. Liq. Cryst. 277 (1996) 343-349.

[16] M. Gibella, A.-S. Crucq, B. Tilquin, P. Stocker, J. Raffi, Utilisation de la RPE et de la TL pour détecter l'irradiation de médicaments, Ann. Experts Chim. 92 (1999) 435441.

[17] M. Gibella, A.-S. Crucq, B. Tilquin, P. Stocker, G. Lesgards, J. Raffi, Electron spin resonance studies of some irradiated pharmaceuticals, Radiat. Phys. Chem. 58 (2000) 69-76.

[18] J. Raffi, J.-P. Agnel, Electron spin resonance identification of irradiated fruits, Radiat. Phys. Chem. 34 (1989) 891-894. 
[19] J.-M. Dolo, E. Pichot, V. Feaugas, Evaluation of some parameters which influence the ESR measurements for the fading study of alanine dosimeters, Appl. Magn. Reson. 15 (1998) 269-277.

[20] N. Yordanov, V. Gancheva, Selfcalibrated alanine/EPR dosimeters: a new generation of solid state/EPR dosimeters, J. Radioanal. Nucl. Chem. 240 (1999) 215-217.

[21] F. Burger, I. Pouliquen-Sonaglia, S. d'Avino, J. Raffi, Etude de l'irradiation gamma du collagène en phase solide et en phase liquide, J. Pharm. Belg. 55 (2000) $145-154$.

[22] H. Shields, P.-J. Hamrick Jr, The influence of crystal structure on radical formation in $\mathrm{X}$-irradiated amino acids, J. Chem. Phys. 64 (1976) 263-270.

[23] A. Minegishi, R. Bergene, P. Riesz, ESR of spin-trapped radicals in gamma-irradiated polycrystalline amino-acids, $N$-acetyl amino acids and dipeptides, Int. J. Radiat. Biol. 38 (1980) 627-650.

[24] D. Hill, R. Garrett, S. Ho, J. O'Donnell, P. O'Sullivan, P. Pomery, Radiolysis of model polypeptiides in the solid state: radiation sensitivity and side chain structure radiat, Phys. Chem. 17 (1981) 163-171.

[25] J. Pilbrow, D. Hutton, Y. Zhong, C. Noble, R. Song, Pulsed EPR investigation of hyperfine structure in gamma-irradiated alanine, Appl. Radiat. Isot. 47 (1996) $1257-1261$.

[26] J. Raffi, J.-P. Agnel, Influence of the physical structure of irradiated starches on their ESR spectra kinetics, J. Phys. Chem. 87 (1983) 2369-2373.

[27] J. Raffi, J.-P. Agnel, S.-R. Kassis, Identification par résoance paramagnétique électronique de céréales irradiées, Sci. Aliments 4 (1987) 657-663.

[28] T. Kudo, H. Heusinger, ESR-spin-trap and UV investigations of solutions of D-glucose and lactose irradiated with ultrasound, Carbohydr. Res. 123 (1983) 41-52.

[29] T. Matsuyama, H. Menhofer, H. Heusinger, ESR spin trap investigations on aqueous glucose solutions irradiated by ultrasound and gamma-rays, Radiat. Phys. Chem. 32 (1988) 735-739.

[30] H. Heusinger, comparison of the reactions induced by ultrasound and gamma rays in aqueous lactose solutions, Ultrasonics 28 (1990) 30-36.

[31] V. Misil, P. Riesz, EPR characterization of free radicals intermediates formed during ultrasound exposure of cell culture media, Free Radic. Biol. Med. 26 (1999) 936-943.

[32] S.-P. Zhang, J. Xie, J.-P. Zhang, J.-Q. Zhao, L.-J. Jiang, Electron spin resonance studies on photosensitized forma- tion of hydroxyl radical by C-phycocyanin from Spirulina platensis, Biochim. Biophys. Acta 1426 (1999) 205-211.

[33] K.J. Reszka, P. Bilski, C.-F. Chignell, J. Dillon, Free radical reactions photosensitized by the human lens compoent, kynurenine: an EPR and spin trapping investigation, Free Radic. Biol. Med. 20 (1996) 23-34.

[34] S.-I. Kondo, S. Hosaka, M. Kuzuya, Mechano-chemical solid state polymerization. VII. Novel composite polymeric prodrugs prepared by mechano-chemical polymerization in the presence of pharmaceutical acids, Chem. Pharm. Bull. 46 (1998) 669-675.

[35] A. Marino, R. Becker, Mechanically induced free radicals in bone, Nature 218 (1968) 466-467.

[36] T. Kudo, H. Heusinger, Formation of mechano-radicals in D-glucose and lactose, Carbohydr. Res. 103 (1982) $7-14$.

[37] M. Desrosiers, M. Simic, F. Eichmiller, A. Johnston, R. Bowen, Mechanically-induced generation of radicals in tooth enamel, Appl. Radiat. Isot. 40 (1989) 1195-1197.

[38] C.J. Kay, Mechanochemical mechanism for peptidyl free radical generation by amyloid fibrils, FEBS Lett. 403 (1997) 230-235.

[39] A. Bertolini, C. Mestres, P. Colonna, J. Raffi, Free radicals formation in the UV and gamma irradiated cassava starch, Carbohydr. Polymers. 44 (2001) 269-271.

[40] A. Bertolini, C. Mestres, J. Raffi, A. Buléon, D. Lerner, P. Colonna, Photodegradation of cassava and corn starches, J. Agric. Food. Chem. 49 (2001) 675-682.

[41] CEN, Detection of irradiated food from which silicate minerals can be isolated, method by thermoluminescence, EN 1788 (1996).

[42] S. Chabane, I. Pouliquen-Sonaglia, J. Raffi, Detection of irradiated spices by different physical techniques, Can. J. Physiol. Pharm. 79 (2001) 1-6.

[43] P. Stocker, M. Gibella, A.-S. Crucq, B. Tilquin, G. Lesgards, J. Raffi, Thermoluminescence de quelques médicaments irradiés, J. Chim. Phys. 96 (1999) 174-177.

[44] J. Raffi, R. Siadous, 1997-1998: a turn in food irradiation, Agro-Food-Industry Hi-Tech, July/August (1998) $31-35$.

[45] CEN, Detection of irradiated food containing fat, gas chromatographic analysis of hydrocarbons, EN 1784 (1996).

[46] G. Lesgards, J. Raffi, I. Pouliquen, A.A. Chaouch, P. Giamarchi, M. Prost, Use of radiation-induced alkanes and alkenes to detect irradiated food containing lipids, J. Am. Oil. Chem. Soc. 70 (1993) 179-185. 